\title{
Multimodality, Argument and the Persistence of Written Text
}

\author{
Lesley Gourlay
}

\begin{abstract}
Multimodal research and theory as applied to higher education has arguably been founded on the view that 'traditional' linguistic written text holds too central a position as the mainstream and valorised form of academic expression. This strand of work has sought to recognise the role and value of non-written forms of semiosis in a range of academic settings. This has led to a focus on the visual in particular as an alternative mode of expression of academic ideas. The increased use of digital mediation in society as a whole and in higher education in particular has underscored what is perceived to be a move away from written text and print literacy processes, artifacts and texts as the primary site of academic representation. It has been suggested in the literature that visual images may be capable of conveying academic argument with minimal or no combination with verbal text (e.g. Barcelo Aspeitia, 2012). This chapter will examine this contention in the very specific context of academic argument, and will argue that - despite the many advantages of multimodal argumentation - the features of conventional written text remain well-suited to the particularly demands of extended and complex development of propositional context and intertextual academic argument. I will argue that some of the features of written academic texts which are often critiqued as exclusionary - particularly its relative stability, specialist generic status and complexity could also be interpreted as conferring access to intertextuality and critique. I will argue that use of visual representation alone to convey academic argument necessarily relies to a large extent on previous shared knowledge of an unseen set of conventional written texts, and as such may struggle to 'stand alone' as an academic argument in terms of accessibility to wide readership and amenability to critique (see also Archer, chapter 5 this volume on multimodality in academic argument).
\end{abstract}

\section{INTRODUCTION}

In what is widely regarded as a foundational text, Kress and Van Leeuwen (2001) argue that in Western culture there has been a tendency towards monomodality across a range of areas 
of social and cultural life, citing the preponderance of un-illustrated text in highly-valued genres of writing as an example. They argue that this has begun to be broken down in contemporary practices, with a greater presence of multimodal texts drawing on a range of semiotic resources, including the visual. Their contention is that "within a given socialcultural domain, the 'same' meanings can often be expressed in different semiotic modes" (Kress \& Van Leeuwen, 2001, p. 1), to substantiate this point is the stated primary aim of the volume. They argue for this partly on the basis of the increased use of digitisation, which brings together modes which may have hitherto not been available for consumption or production via the same device. As they point out, the notion of a 'grammar' of various modes has been posited by a range of authors, such as Martinec (1998) looking at the semiotics of action, O'Toole's (1994) work on the semiotics of images and their own work on images (Kress \& Van Leeuwen, 2006). (It is thought-provoking to note the use of the notion of 'grammar' to denote semiotic systems at work in these modes, as this is a term conventionally associated with language. This seems to imply that language is regarded here as the prototypical semiotic system, against which others should be compared, although it is worth noting that Kress has moved away from this notion in more recent work; see also Hiippala, chapter 3 this volume, on the dominance of written language in research monographs).

They go on to compare the status of language as a system working through double articulation - message as form and meaning. This is contrasted with multimodal texts, which they claim as making meaning in multiple articulations. They use the term 'strata' to theorise multimodal communication - those of discourse, design, production and distribution. They also emphasise the importance of interpretation and an 'interpretive community' - without which communication cannot be said to have taken place. As they point out, interpreters rely on semiotic knowledge of all of the four levels identified above. I will return to these constructs later in this chapter. As they put it:

The field of discursive practice is social and therefore historical, and cannot be understood without a sense of the historical / social contingencies of the arrangement and configuration of practices and modes. Nor can we hope to understand fully the shaping and availability of modes and discourse without a clear sense of the embeddedness of semiosis in the social, and its historical shaping. (Kress \& Van Leeuwen, 2001, p. 43) 
Academic communication relies on argument, a complex concept which may be defined in various ways. For the purposes of this paper I will be using the construct in the sense of "a connected series of statements or reasons intended to establish a position" (Andrews, 1995, p. 3). In argumentation theory, several commentators have argued for a greater recognition of the role of the visual. Birdsell and Groarke (1996) present a special issue of the journal Argumentation and Advocacy which explores the nature and importance of the nonverbal in argument, with a particular emphasis on the visual. Groarke notably continued to develop theories of the visual in argumentation (e.g. Groarke 2002; 2009). Drawing on this and other related work in argumentation theory (e.g. Gilbert 1994; Blair 1996), in a recent paper Barcelo Aspeitia (2012) argues that:

...not all images used in argumentation play a merely illustrative or ornamental role. Instead, in some cases, images can substantially and directly contribute to the one of the key components of argumentation, i.e., the communication of propositional premises and conclusions. (p. 356)

He argues for what he terms heterogeneous arguments (following Barwise, 1993) which draw on both verbal and visual resources. His key claim is that images can convey propositional content without the need for verbalisation. He bases his argument on Stainton's (2006) analysis of subsentential speech, where he proposes that this should not be understood as a form of syntactic ellipsis, but as a subsentential linguistic unit - "a bare phrase" (Barcelo Aspeitia, 2012, p. 357). The argument here is that when uttered in context, phrases which are not grammatically propositional can be grasped as full propositions in context. The example used by Stainton and referred to by Barcelo Aspeitia is reproduced below:

Suppose Alice and Bruce are arguing. Bruce takes the position that there are not really any coloured objects. Alice disagrees. A day or so later, Alice meets Bruce. Having just read G.E. Moore, she offers the following argument. She picks up a red pen, and says 'Red. Right?' Bruce, guileless fellow that he is, happily agrees. Alice continues, "Red things are coloured things. Right?' Bruce nods. At which point Alice springs her trap: 'So Bruce, there is at least one coloured thing. This thing. (Stainton, 2006, p. 181; cited in Barcelo Aspeitia, 2012, p. 358)

He argues that Alice conveyed the proposition not through linguistic ellipsis, but by the subsentential phrase plus the act of holding up the pen. Barcelo Aspeitia (2012) goes on to argue that the same holds for visual images, that they can contribute "novel and necessary information for the communication of arguments, without the need for fully sentential 
reconstruction" (2012, p. 359). He states his main aim as "to topple verbal language from its central place in argumentation, i.e. to show that non-linguistic entities like images can play a role in argumentation as substantial as that of phrases and sentences" (Barcelo Aspeitia, 2012, p. 359). He makes the point that verbal reconstruction of a full verbal proposition is not required in these heterogeneous arguments, a position which contradicts the claims made by other commentators in the field (e.g. Johnson, 2003; Tarnay, 2003; Alcolea-Banegas, 2009). In order for these arguments for be genuinely heterogeneous, Barcelo Aspeitia argues that the visual images must be seen not as mere clues used to recover 'missing' verbal elements, but must themselves be recognised as putting forward premises and conclusions. He uses the following example to illustrate this point:

George and Hanna work at a petting zoo. The petting zoo sells small jars filled with food for the children to feed some of the animals. George and Hannah are in charge of labelling the jars. Instead of using words, they use pictures in their labels. Food for feeding sheep is labelled with a picture of a sheep, food for feeding llamas is labelled with a picture of a llama and so on. They have several jars filled with assorted vegetables, fruits, crackers, etc. Some they recognise easily, but for others it is a little harder. At a certain moment George picks up one of the unidentified jars and asks Hanna about its content. Hanna inspects its content and says 'Let me see. It is mostly hay, but there are some vegetables in there too. I can see some chicory greens, kale, green pepper, red cabbage, and other stuff; but there are no rhubarb leaves or potatoes.' So she takes one of the labels picturing a rabbit, sticks it on the jar and hands it to George. (Barcelo Aspeitia, 2012, p. 364)

It is worth pointing out that both Stainton and Barcelo Aspeitia build their arguments on invented (although plausible) examples of face-to-face spoken interaction, in which the visual element takes the form of gesturing towards or placing artifacts. It is also worth noting that the propositions carried by these visual artifacts are singular, not complex, and are embedded in surrounding verbal propositions. The case they make is a persuasive one for that type of context, but the question remains as to whether the same position can be maintained in the context of complex and sustained academic argument which is conventionally expressed in verbal written means over an extended text, involving a wide of range of specialist lexical items and complex grammatical features such as subordination, with reference to multiple other texts (see also Thesen, chapter 2 this volume, on the importance of gaze in the academic lecture).

Working in contemporary rhetoric, Andrews (2014) also expresses the view that visual images can go beyond illustration and can constitute argument: 
...as far as visual argumentation is concerned, it is clear that images can be used as evidence for claims and propositions. In this role, they go beyond illustration to providing evidence in a court of law, as incontrovertible 'fact' in support of a thesis, or as a diagram of a process to be followed and that is based on a procedure that has been expressed verbally. But images can fulfil the function of claims and propositions themselves because of their multiple signification, and especially if they are juxtaposed with other images and/or they are set in a sequence that allows logical or quasi-logical connection. Their articulation constitutes an argument rather than merely persuading. (Andrews, 2014, p. 85)

Andrews cites as an academic example Strickland's Engladesh, which is no longer available online. This was a multimodal slide sequence submitted as an MA dissertation in Photojournalism at City University, London. The use of visual images and other forms of nonverbal artifact is an established part of academic representation in the creative arts, where students may submit visual or three-dimensional work as a major part of their thesis (See Richards et al., 2012 for a comprehensive exploration of digital and multimodal theses). However, there is still a requirement to provide a written academic commentary to accompany the piece. In Andrews' view, what distinguishes Strickland's piece was the very minimal use of verbal text, leading to an artifact which is almost entirely visual. Richards contends that the sequencing and juxtapositioning of images in the photo essay lead to a visual academic argument in this case. However, it is worth pointing out that Strickland's piece was submitted for a degree in photojournalism, where the photo essay is an established genre, and is it likely that the work was being judged to a large extent on the basis of its merits in terms of that inherently visual discipline and field of creative and professional practice (see also Bell, chapter 7, this volume).

Bayne and Ross (2013) report on a nonverbal 'digital essay' which they used to assess a module as part of an online MA in Digital Education. They focus on a digital artifact created by a student in the virtual world of Second Life ${ }^{\mathrm{TM}}$, focusing on Donna Haraway's (1991) well-known theoretical work on the notion of the cyborg. The student created a virtual 3D 'Imaginarium' in this virtual environment, and deployed a series of images relating to the theme. As they describe it:

Images of pages from books and articles consulted in creating the piece are scattered on the floor, as if in reference to the inadequacy of conventional academic citation norms to take account of the volatility of digital texts. To the left (off screen) is a teleporter which leads to an IMAX-type theatre, on which is displayed a looped video 
of cyborg imagery in films. Downstairs is a Second Life 'chatbot' called Unheimliche ('unhomely') who welcomes visitors and engages them in automated chat, delegating the speaking 'voice' of the essay to a non-human agent in a way which explicitly engages with the notion of the posthuman and its 'literacies. (Bayne \& Ross, 2013, p. 103)

Minimal written text is used, and images of broken cyborgs are deployed throughout. Through this assignment Bayne and Ross explicitly encourage students to 'take a stance against representationalism', from a posthuman perspective, which questions assumptions about the stable and autonomous human author. As they put it:

Here textuality becomes more complex, more diverse, and more visual, as the image and the logic of the screen topples the dominance of the written word and the logic of the printed page. When students engage with new forms of textuality in their academic meaning-making practices, academic discourse becomes newly strange, and the familiar is rendered unfamiliar. (Bayne \& Ross, 2013, p. 103)

Bayne and Ross (2013) deliberately create a challenge for the reader / assessor, as essayist literacy has been deliberately rejected, leading to a shift in act of interpretation required for assessment, which becomes more explicitly dependent on "the intersubjectivity of the assessor and the assessed" (103).

However, it is worth noting that - like Strickland 2008 - this visual artifact and argument was constituted in a medium which was closely associated with a substantive focus of the course, in this case posthumanism and digital textuality. Here the visual has been chosen as a medium of argumentation in order to critique conventional essayist literacy, and also to draw out the substantive points of the module surrounding the radically distributed nature of authorship across the human and nonhuman in digital environments. This is a striking and innovative approach which powerfully disrupts notions of authorship and agency around digital texts. However, given that interpretation of the text depends on the 'intersubjectivity' of the assessor and the assessed, it seems likely that this Imaginarium would not function as a text beyond the context of this course. This may have been an accepted element of this radical pedagogical approach taken by Bayne and Ross, but it does limit the applicability of this type of approach beyond the expression of this very specialist and reflexive point. Additionally, it might be argued that the Imaginarium in a sense presents only one substantive proposition - that authorship, agency and textuality are radically dispersed across human and nonhuman actors. This is a striking and important point within 
the context of this course, but I would argue that this does not constitute a persuasive case for a wholesale rejection of conventional academic writing as a result, given the apparent limitations of this nonverbal approach in terms of sharing meaning beyond that context. Their second example is of a video focusing on the notion of the flaneur, depicting a flyover of Lower Manhattan. This is also a radically different approach to the conventional written essay, however it is accompanied by a voiceover using 'conventional academic prose', and so does not constitute a nonverbal academic argument per se.

Ingraham (2005) presents a case for the possibility of sustaining academic argument without using written verbal text, proposing a BBC programme (BBC 2001) plus accompanying website about prehistoric wildlife as an example. I have already developed an extended critique of Ingraham's chapter (Gourlay, 2012). In summary, my objections centre on the fact that the programme contains verbal commentary throughout, and that the website also deploys written text alongside the images. As above, the argument is carried here primarily by verbal texts, and where the visual images do carry argument it relies on viewers' prior familiarity with the tropes and relatively simple messages conveyed by conventional wildlife documentaries.

The literature reviewed above seems to have established that visual images can be used to express propositions in relatively simple spoken interactions in conjunction with speech (e.g. Barcelo Aspeitia, 2012). In academic contexts, it has been argued that visual images alone can also express argument (e.g. Bayne \& Ross, 2013; Andrews, 2014), although the visual or reflexive nature of these disciplinary contexts and assignments should also be borne in mind. Ingraham (2005) establishes that visual images and video can carry academic argument up to a point, but the persuasiveness of his position was undermined by the presence of heavy verbal scaffolding in the example given. Arguably, the claim that visual images can carry complex academic argument without the support of spoken or written text has yet to be made convincingly in the literature. In the rest of the paper I will argue that although visual images can be deployed to great effect as part of multimodal (or heterogeneous) argument alongside verbal or written text, visual images alone do not confer the features required for the construction of complex and extended academic argument.

\section{AMBIGUITY, METAPHOR AND DENOTATION}


This first difficulty with carrying complex academic argument in predominantly or solely visual formats lies with the precision and clarity that it might offer in terms of communication. Although language is not a static system and is constantly in flux and open to interpretation, it is relatively stable in terms of shared meanings or lexical items and grammatical structures. These shared meanings - although fuzzy and open to contestation are reinforced to some extent by everyday nonacademic language use, formal education, artifacts such as dictionaries, and established generic conventions of academic writing. Concepts may be referred to in a way which assumes a relatively close and precise shared meaning between writer and readers. The importance of precision in this regard can be seen in the prevalence of definitions of terms in academic writing, emphasising the importance of clear and (at least temporarily) stable shared meaning. This seems indispensible when seeking to construct an academic argument, particularly in contexts where a range of interrelated terms are used, or the same terms are used and deployed slightly differently by different authors. Precision and differentiation between closely-related meanings is often at the heart of academic argument, and language - with its enormous range of lexical items provides this. Language should also be seen as in a co-constitutive relationship with the social context of use as opposed to being prior to it - academic enquiry has led to the coinage of range of terms, in order to make the fine and nuanced distinctions required for high-level academic argument. Similarly, grammatical structures are used to communicate exact relationships between these referents. There may be a range of legitimate reasons to critique and question academic genre and conventions, and to seek to explore alternatives. However, language confers access to meanings such as tense and mood, which can be used to communicate a range of complex meanings such as sequence, causality and critique in a generally agreed shared code, and as such seems more suited to complex academic argumentation either used alone or in conjunction with multimodal forms of expression.

In contrast, it might be argued that visual images (I am excluding diagrams and tables here) have conventionally been used to construct meaning in a rather different way symbolically and metaphorically, as opposed to in the more restricted precise denotative relationship offered by a lexical item. An image may be widely recognized, but precisely what it should be understood to denote may be more ambiguous and open to individual interpretation. This becomes more complicated when seeking to construct a complex extended argument by linking a series of propositions together in relationships of comparison, contrast and critique through the justaposition of images, as opposed deploying 
the relative precision of lexis and grammatical structure. How this might be achieved unambiguously and in a shared and agreed format is hard to imagine, and has not yet been exemplified in the literature. In this situation a greater burden of interpretation falls on the reader and their individual standpoint - in Kress and Van Leeuwen's (2001) terms, there is a lack of a stable interpretive community and broad agreement about the meaning of images in terms of the strata of discourse, design, production and distribution.

\section{RELIANCE ON VERBAL / WRITTEN PROPOSITION}

Additionally, it might also be argued that where visual images do succeed in carrying propositions, they do so through reliance on surrounding or preceding verbal texts as scaffolding. As can be seen above, verbal propositions structure the visual in the analysis offered by Barcelo Aspeitia (2012). It could also be argued that meanings conveyed by the student in the nonverbal digital Imaginarium presented in Second Life not only depend on prior knowledge on the part of the author of a highly complex and extended set of written texts, but also prior knowledge of those texts on the part of the 'reader'. In that sense, the example of the images of cyborgs and so on function rather like a citation to prior written texts which must also have been read, as opposed to a denotation of a concept. This is admittedly a fine distinction, as it could be argued that concepts also need prior knowledge and exposure in order to be recognised and shared. However, my point here is that the burden of detailed argumentation still falls on the preceding foundational written texts. The expression of a complex sequence of propositions is not in fact required of the visual Imaginarium, if the assumption is made that the 'knowing' readership (in the form of the course tutors and fellow students) is already familiar with foregoing texts and conceptual framework. The image then comes to stand for a bundle of associated meanings, as opposed to conveying a structured and sequenced set of propositions in the form of an argument. Admittedly this is one case, and it should be acknowledged that all academic argument relies on familiarity with prior texts, but it is difficult to see how - given the problems with precision highlighted above - it would be possible to convey a 'new' academic argument which interweaves prior reading via visual images, without heavy scaffolding in the form of written texts, either co-present with the images or acting as supporting texts without which the image could not be interpreted precisely. 


\section{INTERTEXTUALITY AND AMENABILITY TO CRITIQUE}

In a related point, a final objection might be made to the notion that academic argument can be conveyed purely or predominantly by the use of visual images alone. Literature review and the critique of previous research and theory form an important and necessary part of academic argument. This presents an additional challenge when seeking to present an argument via visual images, in terms of how these might be deployed to refer to and convey in a nuanced and critical way the work of others, theoretical propositions and so on, and how to synthesise, compare and discuss these clearly and unambiguously. It is undeniable that visual images can be a powerful means of conveying critique through pastiche and irony, such as via political cartoons (although again arguably they are reliant on familiarity with news via written and verbal means). However, the dense, precise and closely-argued nature of much academic argumentation in reference to other academics texts seems to demand a system which delivers nuance and can be readily and relatively unambiguously shared with a readership beyond the immediate context of text production- the complexity of language still appears better-suited to the task than images alone. Although it is constantly evolving, language has powerful constructs governing this relative stability as a shared code, such as standard grammar, spelling, and dictionary definitions of lexical items. In addition, it is organised into recognizable written genres which convey 'chunks' of meaning which guide the reader towards a recognition of propositional meaning. Rightly or wrongly, it arguably remains the dominant semiotic mode in education, which also contributes to this stability as a shared and relatively unambiguous semiotic resource, unlike the visual.

\section{CONCLUSION}

In this chapter I have sought to examine the contention that complex academic argument can be expressed solely or predominantly through visual images. Reviewing related literature from learning technologies, argumentation theory and new rhetoric, I have argued that despite offering some thought-provoking or even radical challenges to established conventions of written academic argument and essayist literacies - the examples given did not amount to a persuasive case that visual semiotic resources alone are capable of conferring the level of detail, complexity and precision required for academic argumentation. In the second part of the chapter I argued that this is not possible, due to a series of limitations of the visual 
when compared to linguistic text. These centred on ambiguity of visual images, which I argued leads to a lack of stability in terms of interpretive community. While acknowledging the instability of language itself, and the legitimate criticisms which can be made of academic textual conventions, I contended that written text is still more suited than visual images in those terms due to its more strongly codified and therefore shared nature. I also made the point that visual propositions depend on accompanying or preceding verbal texts (spoken or written) in order to convey meanings in an unambiguous way. My final point was that language remains preferable to visual images for the expression of critique, and also amenability to critique from the readership.

Challenges to conventional essayist literacies are often based on accusations that these genres are exclusionary or needlessly formal - these are all valid criticisms, and the field of multimodality studies offers fresh and radical new ways of expressing academic ideas in an increasingly digital society and academy. However, some of the features of written text can in fact be seen as shared, inclusive and highly generative, whether used alone in 'conventional' texts or in combination with multimodal semiotic resources. What is seen as 'academic writing' is contestable and always emergent and conventions are not fixed and notions of authorship are also amenable to challenge, for example through the radically distributed authorship exhibited in wikis. In this regard, I would suggest that the field guard against an overly oppositional stance which results in 'conventional' texts being demonised as inherently retrograde and therefore problematic. Instead these might be seen as a powerfully generative set of genres which can evolve in response to digital mediation, and in doing so embrace the richness and disruptive potential of multimodal semiosis without sacrificing the precision, shared code and amenability to critique which they confer.

\section{REFERENCES}

Alcolea-Banegas, J. (2009). Visual Arguments in Film. Argumentation, 23, 259-275.

Andrews, R. (1995) Teaching and Learning Argument. London: Cassell.

Andrews, R., Borg, E., Boyd-Davis, S., Domingo, M. \& England, J. (Eds.) (2012). The SAGE Handbook of Digital Dissertations and Theses. London: SAGE. 
Andrews, R. (2014). A Theory of Contemporary Rhetoric. London: Routledge.

Barcelo Aspeitia, A. (2012). Words and Images in Argumentation. Argumentation, 26, 355368.

Bayne, S., \& Ross, J. (2013). Posthuman Literacy in Heterotopic Space: A Pedagogical Proposal. In R. Goodfellow, \& M. Lea (Eds.), Literacy in the Digital University: Critical Perspectives on Learning, Scholarship and Technology (pp.95-110). London: Routledge.

Barwise, Jon. (1993). Heterogenous Reasoning. In J. Barwise \& G. Allwein. (Eds.), Working Papers on Diagrams and Logic (pp. 1-13). Bloomington: Indiana University Logic Group.

BBC 2001. Walking with Beasts: Episode 6 Mammoth Journey. Retrieved December 17, 2014, from https://www.youtube.com/watch?v=No6t6yl_imE.

Birdsell, D., \& Groarke, L. (1996). Toward a Theory of Visual Argument. Argument and Advocacy, 33(1), 1-10.

Blair, J. (1996). The Possibility and Actuality of Visual Arguments. Argumentation and Advocacy, 33, 23-39.

Gilbert, M. (1994). Multi-Modal Argumentation. Philosophy of the Social Sciences, 24, 159177.

Gourlay, L. (2012). Media Systems, Multimodality and Posthumanism. In Andrews, R., Borg, E., Boyd-Davis, S., Domingo, M. \& England, J. (Eds.), The SAGE Handbook of Digital Dissertations and Theses (pp. 85-100). London: SAGE.

Groarke, L. (2002). Towards a Pragma-Dialectics of Visual Argument. In F. van Eemeren (Ed.), Advances in Pragma-Dialectics (pp. 137-151). Amsterdam: SicSat. 
Groarke, L. (2009). Five Theses on Toulmin and Visual argument. In F. van Eemeren \& B. Garssen (Eds.), Pondering on Problems of Argumentation: Twenty Essays on Theoretical Issues (pp. 229-239). Amsterdam: Springer.

Haraway, D. (1991). A Cyborg Manifesto: Science, Technology and Socialist-Feminism in the Late Twentieth Century. In D. Haraway, Simians, Cyborgs and Women: The Reinvention of Nature (pp. 149-181). New York: Routledge.

Ingraham, B. (2005). Ambulating with Mega-Fauna. In R. Land \& S. Bayne. Education in Cyberspace (pp. 45-54). Abingdon: RoutledgeFalmer.

Johnson, R. (2003). Why Visual Arguments Aren't Arguments. In IL@25. A Conference Celebrating the Twenty-Fifth Anniversary of the First International Symposium on Informal Logic. Retrieved April 29, 2015, from http://web2.uwindsor.ca/courses/philosophy/johnsoa/visargtext.htm.

Kress, G. (2003). Literacy in the New Media Age. London: Routledge.

Kress, G., \& Van Leeuwen, T. (2001). Multimodal Discourse: The Modes and Media of Contemporary Communication. London: Routledge.

Kress, G., \& Van Leeuwen, T. (2006). Reading Images: The Grammar of Visual Design (2 ${ }^{\text {nd }}$ ed.). London: Routledge.

Martinec, R. (1998). Cohesion in Action. Semiotica, 120(1-2), 161-180.

O’Toole, M. (1994). The Language of Displayed Art. Leicester: Leicester University Press.

Stainton, R. (2006). Words and Thoughts: Subsentences, Ellipsis and the Philosophy of Language. Oxford: Oxford University Press.

Tarnay, L. (2003). The Conceptual Basis of Visual Argumentation. In F. van Eemeren, J. Blair, C. Willard \& A. Snoeck Henkemans (Eds.), Proceedings of the Fifth Conference 
International Society for the Study of Argumentation (pp. 1001-1005). Amsterdam:

International Centre for the Study of Argumentation. 